\title{
Refining risk in diabetes and CAD with SPECT MPI: New insights and future challenges
}

\author{
Syed Y. Naqvi, MD, ${ }^{a}$ Steven D. Wittlin, $M D,{ }^{b}$ and Ronald G. Schwartz, MD, $M S^{a, c}$ \\ a Department of Medicine, Cardiology Division, University of Rochester Medical Center, \\ Rochester, NY \\ b Department of Medicine, Endocrine-Metabolism Division, University of Rochester Medical \\ Center, Rochester, NY \\ c Department of Imaging Sciences, Nuclear Medicine Division, University of Rochester Medical \\ Center, Rochester, NY
}

Received Nov 21, 2017; accepted Nov 21, 2017

doi: 10.1007/s12350-017-1177-4

\section{See related article, 1093-1102}

Diabetes mellitus (DM) is an expanding global epidemic. Estimates of a global prevalence of 415 million people and total health expenditure of 673 billion US dollars have been reported. ${ }^{1}$ The prevalence of individuals between 20 and 79 years with diabetes is predicted to rise to 642 million by $2040 .{ }^{1}$ Assessment of morbid risk of diabetes is of substantial importance in the allocation of resources to address the human and financial burdens of this growing global health threat. Epidemiological studies have demonstrated that diabetes places patients at an elevated risk for developing coronary artery disease $(\mathrm{CAD}){ }^{2,3}$ A large meta-analysis of 102 studies confirmed a two-fold excess risk for vascular disease in DM. ${ }^{4}$ Since the landmark study by Haffner first reported the equivalence of risk of diabetes and $\mathrm{CAD},{ }^{5}$ widespread controversy has ensued with several studies, which have supported ${ }^{6-10}$ or challenged ${ }^{11-17}$ the concept of risk equivalent of DM and CAD.

The substantial incremental risk assessment of radionuclide SPECT MPI compared to the exercise ECG

Reprint requests: Ronald G. Schwartz, MD, MS, Department of Medicine, Cardiology Division, University of Rochester Medical Center, Box 679-N, 601 Elmwood Avenue, Rochester, NY 14642; ronald_schwartz@urmc.rochester.edu

J Nucl Cardiol 2019;26:1103-6.

$1071-3581 / \$ 34.00$

Copyright (C) 2018 American Society of Nuclear Cardiology. and echocardiography reported in referred populations suggests its role to refine the heterogeneity of risk in patient populations with CAD and/or DM. ${ }^{18-20}$ The DIAD study reported that $22 \%$ of asymptomatic diabetic patients had myocardial ischemia on adenosine Tc-99 m SPECT MPI ${ }^{18}$ and subsequent COURAGE, INSPIRE, and BARI-2D trials confirmed the powerful incremental risk assessment with SPECT MPI as well as favorable effects of optimal medical therapy in patients with CAD and/or DM. ${ }^{21-23}$

In the current issue of the Journal of Nuclear Cardiology, Morales et al. report a large retrospective analysis of 17,499 patients undergoing SPECT MPI at a single tertiary center from 1996 to $2006 .^{24}$ The study explores the interaction of risks of subsequent hard coronary events identified by diabetes mellitus, history of CAD, and the presence of greater than mild stress perfusion defect (SSS $\geq 4)^{24}$ equivalent to a $6 \%$ total stress LV perfusion defect score. Patients were divided into four groups based on CAD and DM status at the time of initial imaging: non-DM patients without CAD $(N=9133)$, non-DM patients with CAD $(N=3906)$, DM patients without CAD $(N=2768)$, and DM patients with CAD $(N=1692)$. These four groups were further divided based on summed stress score (SSS) $<4$ or $\geq 4$ to classify normal and abnormal perfusion, respectively. Yearly event rate for the composite end point of cardiac death or non-fatal myocardial infarction (MI) was calculated over a mean follow-up of $2.4 \pm 1.5$ years with a maximum of 5 years.

As expected, SPECT MPI did contribute incremental risk assessment to patients with $\mathrm{CAD}$ and/or DM. Although the rates of events in patients with diabetes without CAD and those with CAD without diabetes were similar by inter-group comparison, robust 
survival analysis demonstrated that the incidence of adverse cardiac event rate was slightly lower among DM subjects without CAD compared to non-diabetic subjects with CAD $(5.5 \%$ vs $7.1 \%$, respectively, $P<0.001)$. The greatest risk of cardiac death and nonfatal MI was observed in DM subjects with CAD \{HR 3.7 (95\% CI 3.02-4.50) $P<0.001\}$. Within these diabetic patients with $\mathrm{CAD}$, the presence or absence of SPECT perfusion defects $(\mathrm{SSS} \geq 4)$ identified a nearly 3 -fold difference in event rate: $6.6 \%$ vs $2.3 \%$. In patients without diabetes or $\mathrm{CAD}$, the presence or absence of SPECT perfusion defects identified a 4.5 -fold difference in events. A normal SPECT MPI was associated with a hard event rate of well under $1 \%(0.6 \%)$ in the groups of non-diabetic patients without CAD. Normal SPECT studies identified patients with more than $1 \%$ hard events in patients with CAD (1.4\%) or with DM (1.6\%), which were similar. Abnormal perfusion by SPECT identified the same $3.5 \%$ event rate in non-diabetic patients with CAD and Diabetic patients without CAD.

Study limitations should be recognized which may have contributed to the observed rates of events between the diabetic and CAD groups. Table 1 in the article identifies major differences of inter-group use of statins, aspirin, beta-blockers and ACE inhibitors. More prevalent use of statins and use of intensive statin therapy recommended by current 2013 lipid guidelines in the diabetic patients without $\mathrm{CAD}$ in the current era might influence inter-group differences. In this study, the categorization of diabetes was based on self-reporting of patients; thus, unknown differences in the duration and severity of DM assessed by A1C may have influenced results. This consideration is important because $25 \%$ of acute MI patients in the era of this study (1996-2006) had unrecognized T2DM. ${ }^{25}$ The distinction of Type I and Type II DM was not made in this study, and a recurring question of the risk and treatment response of these diabetic groups persists. BMI was higher in the DM groups, and neither attenuation correction nor parallel hole CZT SPECT MPI was used, which enhances diagnostic accuracy for detection of angiographic stenosis in obese patients. ${ }^{26}$

The findings of this landmark Morales study support the concept of CAD risk equivalence of diabetes and CAD in a population more than seven times larger than that studied in the original Haffner East West study. ${ }^{5}$ They also support AHA guidelines which recommend treating CAD risk factors in DM patients without $\mathrm{CAD}$ as aggressively as in non-diabetic patients with $\mathrm{CAD} .{ }^{27}$ The study firmly establishes the role of SPECT MPI to refine incremental risk assessment in patients with diabetes and/or CAD and has implications for envisioning further research to personalize strategies for optimal therapy in these patients.

\section{RISK ASSESSMENT BEYOND SPECT PERFUSION}

Data for the Morales study began more than two decades ago. Has it underestimated the robust risk assessment afforded by routine contemporary techniques of nuclear cardiology, including ECG-gated post-stress LVEF and LV volume indices by gender, ${ }^{28}$ transient ischemic dilation, ${ }^{29}$ quantitative flow reserve by PET $^{30-32}$ or CZT SPECT now commercially available, I-123-MIBG, and TTR cardiac amyloid assessments with Tc-99 $\mathrm{m}$ pyrophosphate ${ }^{33}$ in our aging population, and assessment of cardiac dyssynchrony with single injection SPECT MPI? ${ }^{34}$ These techniques may provide substantial opportunities for incremental risk assessment in the growing worldwide epidemics of diabetes mellitus, ischemic heart disease, and heart failure.

A major lesson we learned from the DIAD (Detection of Ischemia in Asymptomatic Diabetes) is that routine screening of asymptomatic patients with diabetes and normal resting electrocardiograms is not justified, because of the relatively low yield of significant abnormalities, the low overall cardiac event rate with contemporary medical therapy, and the lack of clinical impact of screening on events in patients receiving routine, goal-directed medical therapy. However, DIAD reported a simple clinical bedside testing of autonomic dysfunction measured by a Valsalva test to quantify that heart rate variability in the clinic was highly predictive of myocardial ischemia in the $22 \%$ of patients found to have ischemia by adenosine Tc-99 $\mathrm{m}$ SPECT MPI in DIAD. Whether a simple, rapid inexpensive clinical assessment of autonomic dysfunction with heart rate variability can identify a very low-risk group of diabetic patients alone or in combination with coronary calcium scoring, and stress only SPECT MPI and delay of routine goal directed medical therapy remains an important hypothesis for further research.

A major trend of imaged populations has been the declining pretest risk and prevalence of events in tested populations, ${ }^{35}$ ironically reflecting improved prevention and treatment strategies of clinically defined populations as our imaging techniques over time have improved. Concurrently, as our population over time becomes older, fatter, and more insulin resistant, the rate of decline of cardiac morbidity will probably decrease. Although goal-directed medical therapy such as routine statin use provides populations of patients with diabetes favorable outcomes, a substantial minority of patients do not tolerate or want high-intensity statin therapy if they do not require it. Can a personalized medicine approach help identify the substantial minority of very low-risk patients in whom intensive statin therapy can be safely delayed or avoided, reduce adverse medications effects, and improve quality of life? Is the widely reported $10 \%$ 
LV ischemia burden threshold associated with improved outcome with revascularization ${ }^{36}$ the same or different in CAD patients with or without DM?

With the burgeoning global epidemics of diabetes and $\mathrm{CAD}$, the field of nuclear cardiology is challenged to stay on track with patient-centered appropriate use testing ${ }^{37}$ and to define patient-centered strategies of risk assessment and management that deliver better outcomes in diabetes and ischemic heart disease than that provided by routine goal-directed medical therapies for these conditions. The best interests of public health are indebted to the substantial historic study of Morales, which has positioned the field of nuclear cardiology on a large scale to evaluate these challenges to optimize cost effective health care and patient satisfaction outcomes in the 21 st century.

\section{Disclosure}

Dr. Syed Y. Naqvi reports no industry relationships. Dr. Steven D. Wittlin reports he is on the speakers bureau of Medtronics. Dr. Ronald G. Schwartz reports he is on the speakers bureau of Astellas.

\section{References}

1. Ogurtsova K, da Rocha Fernandes JD, Huang Y, et al. IDF diabetes atlas: global estimates for the prevalence of diabetes for 2015 and 2040. Diabetes Res Clin Pract 2017;128:40-50.

2. Stamler J, Vaccaro O, Neaton JD, Wentworth D. Diabetes, other risk factors, and 12-yr cardiovascular mortality for men screened in the multiple risk factor intervention trial. Diabetes Care 1993;16:434.

3. Pyorala K, Laakso M, Uusitupa M. Diabetes and atherosclerosis: an epidemiologic view. Diabetes Metab Rev 1987;3:463-24.

4. Sarwar N, Gao P, Seshasai SR, et al. Diabetes mellitus, fasting blood glucose concentration, and risk of vascular disease: a collaborative meta-analysis of 102 prospective studies. Lancet 2010;375:2215-22.

5. Haffner SM, Lehto S, Rönnemaa T, Pyörälä K, Laakso M. Mortality from coronary heart disease in subjects with type 2 diabetes and in nondiabetic subjects with and without prior myocardial infarction. N Engl J Med 1998;339:229-34.

6. Buyken AE, von Eckardstein A, Schulte H, Cullen P, Assmann G. Type 2 diabetes mellitus and risk of coronary heart disease: results of the 10-year follow-up of the PROCAM study. Eur J Cardiovasc Prev Rehabilit 2007;14:230-36.

7. Bulugahapitiya U, Siyambalapitiya S, Sithole J, Idris I. Is diabetes a coronary risk equivalent? Systematic review and meta-analysis. Diabetic Med 2009;26:142-48.

8. Saely CH, Rein P, Vonbank A, Huber K, Drexel H. Type 2 diabetes and the progression of visualized atherosclerosis to clinical cardiovascular events. Int J Cardiol 2013;167:776-80.

9. Vaccaro O, Eberly LE, Neaton JD, Yang L, Riccardi G, Stamler J. Impact of diabetes and previous myocardial infarction on longterm survival: 25-year mortality follow-up of primary screenees of the Multiple Risk Factor Intervention Trial. Arch Intern Med 2004;164:1438-43.
10. Evans JM, Wang J, Morris AD. Comparison of cardiovascular risk between patients with type 2 diabetes and those who had had a myocardial infarction: cross sectional and cohort studies. BMJ 2002;324:939-42.

11. Grundy SM, Benjamin IJ, Burke GL, et al. Diabetes and cardiovascular Disease. Circulation 1999;100:1134.

12. Carson AP, Tanner RM, Yun H, et al. Declines in coronary heart disease incidence and mortality among middle-aged adults with and without diabetes. Ann Epidemiol 2014;24:581-87.

13. Giri S, Shaw LJ, Murthy DR, et al. Impact of diabetes on the risk stratification using stress single-photon emission computed tomography myocardial perfusion imaging in patients with symptoms suggestive of coronary artery disease. Circulation 2002;105:32-40.

14. Saely CH, Aczel S, Marte T, Langer P, Drexel H. Cardiovascular complications in Type 2 diabetes mellitus depend on the coronary angiographic state rather than on the diabetic state. Diabetologia. 2004;47:145-46.

15. Hage FG, Lusa L, Dondi M, Giubbini R, Iskandrian AE. Exercise stress tests for detecting myocardial ischemia in asymptomatic patients with diabetes mellitus. Am J Cardiol 2013;112:14-20.

16. Caobelli F, Haaf P, Chronis J, et al. Prognostic usefulness of cardiac stress test modalities in patients with type 2 diabetes mellitus who underwent myocardial perfusion scintigraphy (from the basel asymptomatic high-risk diabetics' outcome trial). Am J Cardiol 2017;120:1098-103.

17. Acampa W, Petretta M, Daniele S, et al. Incremental prognostic value of stress myocardial perfusion imaging in asymptomatic diabetic patients. Atherosclerosis 2013;227:307-12.

18. Wackers FJTh, Young LH. Lessons learned from the detection of ischemia in asymptomatic diabetics (DIAD) study. J Nuclear Cardiol 2009; 16:855-59.

19. Gibbons RJ, Hodge DO, Berman DS, et al. Long-term outcome of patients with intermediate-risk exercise electrocardiograms who do not have myocardial perfusion defects on radionuclide imaging. Circulation 1999;100:2140-45.

20. Marwick TH, Case C, Vasey C, Allen S, Short L, Thomas JD. Prediction of mortality by exercise echocardiography. Circulation 2001;103:2566.

21. Boden WE, O'Rourke RA, Teo KK, et al. Optimal medical therapy with or without PCI for stable coronary disease. N Engl J Med 2007;356:1503-16. https://doi.org/10.1056/nejmoa070829.

22. Mahmarian JJ, Shaw LJ, Olszewski GH, et al. Adenosine sestamibi SPECT post-infarction evaluation (INSPIRE) trial: a randomized, prospective multicenter trial evaluating the role of adenosine Tc-99 $\mathrm{m}$ sestamibi SPECT for assessing risk and therapeutic outcomes in survivors of acute myocardial infarction. $\mathrm{J}$ Nucl Cardiol 2004;11:458-69.

23. Shaw LJ, Cerqueira MD, Brooks MM, et al. Impact of left ventricular function and the extent of ischemia and scar by stress myocardial perfusion imaging on prognosis and therapeutic risk reduction in diabetic patients with coronary artery disease: results from the Bypass Angioplasty Revascularization Investigation 2 Diabetes (BARI 2D) trial. J Nucl Cardiol 2012;19:658-69. https://doi.org/10.1007/s12350-012-9548-3 Epub 2012 Apr 19.

24. Morales DCV, Bhavnani SP, Ahlberg AW, et al. Coronary risk equivalence of diabetes assessed by SPECT-MPI. J Nucl Cardiol 2017. https://doi.org/10.1007/s12350-017-1114-6.

25. Norhammar A, Tenerz A, Nilsson G, et al. Glucose metabolism in patients with acute myocardial infarction and no previous diagnosis of diabetes mellitus: a prospective study. Lancet 2002;359:2140-44

26. Nakazato R, Slomka PJ, Fish M, et al. Quantitative high-efficiency cadmium-zinc-telluride SPECT with dedicated parallel-hole 
collimation system in obese patients: results of a multi-center study. J Nucl Cardiol 2015;22:266-75.

27. Fox CS, Golden SH, Anderson C, et al. Update on prevention of cardiovascular disease in adults with type 2 diabetes mellitus in light of recent evidence. Circulation 2015;132:691-18.

28. Wexler O, Yoder SR, Elder JL, et al. Effect of gender on cardiovascular risk stratification with ECG gated SPECT left ventricular volume indices and ejection fraction. J Nucl Cardiol 2009;16:28-37.

29. Thomas GS, Miyamoto MI, Morello AP 3rd, et al. Technetium $99 \mathrm{~m}$ sestamibi myocardial perfusion imaging predicts clinical outcome in the community outpatient setting. The Nuclear Utility in the Community (NUC) Study. J Am Coll Cardiol 2004;43:21323.

30. Murthy VL, Naya M, Foster CR, et al. Improved cardiac risk assessment with noninvasive measures of coronary flow reserve. Circulation 2011;124:2215-24.

31. Ziadi MC, Dekemp RA, Williams KA, et al. Impaired myocardial flow reserve on rubidium- 82 positron emission tomography imaging predicts adverse outcomes in patients assessed for myocardial ischemia. J Am Coll Cardiol 2011;58:740-48.

32. Taqueti VR, Hachamovitch R, Murthy VL, et al. Global coronary flow reserve is associated with adverse cardiovascular events independently of luminal angiographic severity and modifies the effect of early revascularization. Circulation 2015;131:19-27.

33. Bokhari S, Morgenstern R, Weinberg R, et al. Standardization of 99mTechnetium pyrophosphate imaging methodology to diagnose
TTR cardiac amyloidosis. J Nucl Cardiol 2016. https://doi.org/ 10.1007/s12350-016-0610-4.

34. Friehling M, Chen J, Saba S, et al. A prospective pilot study to evaluate the relationship between acute change in left ventricular synchrony after cardiac resynchronization therapy and patient outcome using a single-injection gated SPECT protocol. Circ Cardiovasc Imaging 2011;4:532-39.

35. Rozanski A, Gransar H, Hayes SW, et al. Temporal trends in the frequency of inducible myocardial ischemia during cardiac stress testing: 1991 to 2009. J Am Coll Cardiol 2013;61:1054-65.

36. Hachamovitch R, Rozanski A, Shaw LJ, et al. Impact of ischaemia and scar on the therapeutic benefit derived from myocardial revascularization vs. medical therapy among patients undergoing stress-rest myocardial perfusion scintigraphy. Eur Heart J 2011;32:1012-24. https://doi.org/10.1093/eurheartj/ehq500.

37. Wolk MJ, Bailey SR, Doherty JU, ACCF/AHA/ASE/ASNC/ HFSA/HRS/SCAI/SCCT/SCMR/STS, et al. 2013 multimodality appropriate use criteria for the detection and risk assessment of stable ischemic heart disease: a report of the American College of Cardiology Foundation Appropriate Use Criteria Task Force, American Heart Association, American Society of Echocardiography, American Society of Nuclear Cardiology, Heart Failure Society of America, Heart Rhythm Society, Society for Cardiovascular Angiography and Interventions, Society of Cardiovascular Computed Tomography, Society for Cardiovascular Magnetic Resonance, and Society of Thoracic Surgeons. J Am Coll Cardiol 2014;63:380-406. 